Economic Education Journal

Volume.1, Issu.1 January 2019, 35-43

http://ejurnal.ung.ac.id/index.php/jej

\title{
Efektivitas Penggunaan Media Vibermixo Dalam Meningkatkan Motivasi Belajar Siswa Pada Mata Kuliah Akuntansi: Berdasarkan Tinjauan Literatur
}

\author{
Mattoasi \\ Universitas Negeri Gorontalo, Gorontalo, Indonesia \\ mattosuming@gmail.com
}

\begin{abstract}
Learning is a complex and unique process, meaning that someone who learns involves all aspects of his personality, both physically and mentally. The involvement of all aspects of personality is expected to have an impact on students with the support of adequate learning media. The purpose of this study is to find out the appropriate learning media in the accounting sphere based on the literature. The research method used is a qualitative method by using library research as a data source. The results showed that the use of Vibermixo media in the accounting learning process could be used to improve the quality with student.
\end{abstract}

\section{ARTICLE HISTORY \\ Received 16 Oktober 2018 \\ Accepted 10 Desember 2018 \\ KEYWORDS \\ Learning Process; Instructional Media; Vibermixo; Accounting Courses; Quality Of Student Learning.}

\section{Pendahuluan}

Perkembangan teknologi saat ini cenderung akan memberi pengaruh kepada segenap bidang kehidupan termasuk dalam bidang pendidikan (Garcia-Fenalfo \& Hernandes-Garcia, 2017). Perubahan ini menyebabkan sebagian besar siswa telah mengenal Teknologi Informasi dan Komunikasi (Sean, Joseph dan Nicholas, 2006). Keadaan ini memudahkan kepada pihak pendidik di dalam melakukan transfer pengetahuan kepada mereka seperti yang diuraikan oleh Hart (2001) bahwa dengan menggunakan media pembelajaran berbasis informasi tekhnologi dan komunikasi dapat memudahkan pendidik dan peserta didik di dalam memahami setiap materi sehingga objektif pembelajaran dapat dicapai.

Penggunaan media pembelajaran dengan memanfaatkan teknologi informasi dan komunikasi juga sejalan dengan (Dit. PSMA 2017) yang mengharapkan agar praktek pembelajaran dewasa ini dalam setiap satuan pendidikan diharapkan mampu

Jambura : Economic Education Journal,Volume. 1, Issue. 1 January 2019. 
menyesuaikan praktek pembelajaran abad 21 agar dapat mempersiapkan siswa dalam menghadapi tantangan global (Dit. PSMA 2017). Demikian juga Alavi, Yoo, dan Douglas (2001) bahwa penggunaan media yang lebih efektif dan menarik siswa dalam proses belajar, maka mereka diharapkan dapat memahami secara komprehensif terhadap setiap permasalahan yang dikaji.

Berkaitan dengan pentingnya penggunaan media dalam pembelajaran juga sejalan dengan beberapa hasil penelitian seperti Febriyanto (2012) menyatakan bahwa menggunakan media dalam pembelajaran dapat meningkatkan hasil belajar siswa dalam mata pelajaran IPS . Sejalan dengan Silfani (2015) yang mendapati bahwa penggunaan media pembelajaran dalam proses pembelajaran kepada peserta didik mempunyai pengaruh terhadap aktivitas belajar siswa dalam mata pelajaran Ekonomi.. Demikian juga beberapa hasil penelitian menyatakan bahwa penggunaan media pembelajaran dapat membantu siswa untuk mencapai prestasi belajar yang lebih baik (Cici Fatma, 2015).

Berdasarkan Beberapa hasil penelitian terdahulu, menunjukkan bahwa penggunaan media dalam pembelajaran dapat meningkatkan prestasi belajar siswa. Namun demikian dari beberapa hasil penelitian, secara jelas bahwa belum ditemui hasil penelitian yang berkaitan dengan penggunaan media pembelajaran dengan menggunakan VIBERMIXO yang menyataukan materi ajar, animasi, grafik, audio visual, gambar dan pena penunjuk, apalagi yang digunakan di dalam pembelajaran mata pelajaran akuntansi yang selama ini menurut Meigs and Meigs, Bettner, dan Whittington (1996) dan Dupree dan Marder (1984) serta Welsch dan Short (1987) dipandang sebagai suatu seni di dalam melakukan pencatatan dan pengelompokan bukti-bukti transaksi organisasi serta meringkaskan dalam neraca saldo dan menyajikan dalam laporan keuangan.

\section{Kajian Teori}

\section{Media Pembelajaran}

Berbagai pakar telah memberikan pandangan tentang media pembelajaran. Bruner (1957) yang menyatakan bahwa media belajar dapat membantu peserta didik dalam memahami setiap permasalahan sehingga peserta didik dapat membangun ide atau konsep baru berdasarkan pengetahuan mereka saat ini / masa lalu. Demikian juga pendapat Clark dan Salamon (1986) bahwa nilai suatu media pembelajaran dapat dilihat dari tingkat realistiknya dalam proses penanaman konsep ia membuat jenjang berbagai jenis media mulai yang paling nyata ke yang paling abstrak.

Tidak jauh berbeda dengan pandangan ahli yang lain dalam bidang pendidikan seperti Dale (1969) yang menyatakan bahwa bagaimana seorang menggunakan setiap media atau sarana untuk meningkatkan pembelajaran sehingga siswa tetap tertarik dari proses yang sedang berjalan. Demikian juga Briggs and Wager (1981) menjelaskan bahwa media adalah segala alat fisik yang dapat menyajikan pesan serta merangsang siswa untuk belajar. Manakala Gagne (1985) berpendapat bahwa media adalah berbagai jenis komponen

Jambura : Economic Education Journal,Volume. 1, Issue. 1 January 2019. 
dalam lingkungan siswa yang dapat merangsangnya untuk belajar.

Berdasarkan beberapa uraian tentang media, maka dapat diringkaskan bahwa media pembelajaran sebagai suatu alat yang dapat membantu seorang guru atau dosen dalam proses belajar mengajar sehingga peranan mereka dapat dikurangi. Hal ini menurut Dimas, Erna, Irama (2016) bahwa dengan menggunakan media pembelajaran yang sesuai dapat merangsang siswa dalam memahami setiap materi ajar yang dijelaskan.

\section{Pentingnya Media Pembelajaran}

Mengapa media pembelajaran penting? Beberapa penelitian menjelaskan bahwa media pembelajaran dapat mendukung tercapainya tujuan pembelajaran. Laurillard (2002); Moran, Seaman, TintiKane dan Babson (2011); Aguswedi (2011) bahwa dengan kemajuan ilmu pengetahuan dan teknologi diharapkan dapat memperngaruhi pola pikir pendidik di dalam memfasilitasi kebutuhan belajar siswanya agar pemahaman mereka lebih baik. Hal ini menjadi penting karena kualitas seorang pendidik dalam setiap keadaan menjadi perhatian yang paling utama di dalam meningkatkan mutu pendidikan.

Tidak jauh berbeda dengan hasil penelitian yang lain seperti Haryanto (2012), Luh Putu Spyana Wati dan Kadek Yogi Parta Lesmana (2016), Saputra (2015), Ratminingsih (2016); Risa Panti Ariani, Ni Made Suriani, Ni Wayan Marti (2014); dan Suweken-Gede (2013) usaha guru untuk menggunakan media pembelajaran yang sesuai, karena media tersebut dapat menyalurkan pesan, dapat merangsang pikiran, perasaan, dan kemauan peserta didik sehingga dapat mendorong terciptanya proses belajar pada diri peserta didik. Demikian juga pandangan Clark (1983); Liu, Liao, Pratt (2009); Bull, Thompson, Searson, Garofalo (2008) dan Chen dan Bryer (2012) bahwa dengan menggunakan media pembelajaran selain untuk memudahkan proses belajar mengajar berlangsung dengan baik, maka media juga dapat meningkatkan efisiensi belajar siswa serta dapat menjaga relevansi dengan tujuan belajar serta konsentrasi mahasiswa yang lebih baik.

\section{Jenis-Jenis Media Pembelajaran}

Berdasarkan beberapa uraian yang berkaitan dengan pentingnya media belajar dalam pembelajaran telah dibuktikan oleh beberapa hasil penelitian sebelum ini. Andi Kristanto (2016) menyatakan bahwa penggunaan media pembelajaran telah merangsang perhatian, minat, pikiran, dan perasaan siswa dalam kegiatan belajar dalam mencapai tujuan belajar pada sekolah menengah. Demikian juga Cici Fatmah (2015) bahwa penggunaan media LCD memberi bukti terhadap peningkatan hasil belajar siswa. Tidak jauh berbeda dengan hasil penelitian Silfani (2015) bahwa penggunaan media pembelajaran berpengaruh terhadap aktivitas belajar siswa. Berkaitan dengan penggunaan media pembelajaran juga sejalan dengan hasil penelitian yang dilakukan oleh Febriyanto (2012) bahwa dengan menggunakan Lembaran Kerja Siswa (LKS) dapat meningkatkan hasil belajar siswa pada kelas VII SMP Negeri 12 Gorontalo.

Jambura : Economic Education Journal,Volume. 1, Issue. 1 January 2019. 
Begitu pentingnya penggunaan model pembelajaran dalam meningkatkan kualitas belajar dan hasil belajar siswa maka juga sejalan dengan hasil penelitian Maulid ( 2017) yang menemukan bahwa penggunaan media Vibermixo dengan menyatukan materi ajar, animasi, grafik, audio visual, gambar dan pena penunjuk dapat membantu siswa di dalam meningkatkan kualitas belajar. Demikian juga Maulid (2018) bahwa dengan menggunakan konsep Eril GB-GK maka siswa diharapkan dapat memahami materi ajar yang lebih baik dengan dukungan penggunaan media Vibermixo.

Metodelogi Penelitian

Penelitian ini menggunakan kajian pustaka (Library Research) di dalam mengumpulkan data-data dan menganalisisnya terhadap hasil penelitian yang berkaitan dengan jenis media pembelajaran. Hal ini untuk mendapatkan suatu media pembelajaran yang tepat di dalam proses belajar mengajar akuntansi yang berkaitan dengan kas, piutang, persediaan, sesuatu yang dibayar dimuka, perlengkapan dan peralatan serta setiap unsur kewajiban dan modal organisasi, sangat dibutuhkan media dalam pembelajaran, agar tercapai efektivitas belajar yang sesuai sehingga siswa dapat lebih memahami terhadap permasalahan yang diteliti.

Dalam penelitian ini metode yang digunakan adalah metode kualitatif. Metode ini menurut beberapa penulis seperti Lebar (2012) dan Tracy (2010) Yin (2014) Yin (2009); Marohaini (2013); Merriam (2009); Miles,Huberman dan Saldana (2014); Ridder dan Hoon (2009); Baker (2014); Creswell (2013); Denzin (2010); Leavy (2014) menyatakan bahwa peneliti kualitatif dapat menggunakan beberapa jenis data (triangulation) di dalam menghasilkan data penelitian, seperti observasi, data dokumen, dan data wawancara dan dapat menggunakan kajian pustaka untuk mengungkapkan suatu fenomena lapangan.

Demikian juga pendapat yang lain seperti Braun \& Clarke, 2013; Miles et al., 2014; Patton (2015); Richards \& Morse(2013) yang menyatakan dengan menggunakan metode pengumpulan data yang beragam diharapkan dapat menghasilkan hasil penelitian yang lebih baik dan lebih mendalam terhadap suatu fenomena yang dikaji. Sebab menurut Kemp dan Dayton (1985) dan Hamalik (1994) dan media pembelajaran memberi manfaat dalam membangkitkan keinginan dan minat yang baru, membangkitkan motivasi dan rangsangan kegiatan belajar, dan bahkan membawa pengaruh-pengaruh psikologis terhadap siswa.

\section{Hasil Penelitian}

Berdasarkan data dan informasi yang diperoleh dari kajian pustaka menunjukkan bahwa penggunaan media dalam proses belajar mengajar sangat diperlukan. Oleh karena itu beberapa media pembelajaran yang dapat digunakan menurut berbagai literature seperti; teks, media video, media visual; media proyeksi gerak; benda-benda tiruan dan manusia. Beberapa tujuan dari penggunaan media yaitu dapat memudahkan proses belajar; meningkatkan efisiensi belajar siswa, meningkatkan efektivitas belajar, menjaga relevansi dengan tujuan belajar; sehingga konsentrasi siswa akan fokus pada materi yang diajarkan.

Jambura : Economic Education Journal,Volume. 1, Issue. 1 January 2019. 
Selain jenis-jenis dan tujuan media pembelajaran, maka beberapa fungsi dari media pembelajaran adalah memberi rangsangan siswa untuk belajar; memberi materi instruksional; sebagai teknologi pembawa informasi atau pesan kepada siswa. Sementara itu manfaat yang diharapkan dalam media pembelajaran adalah penyampaian materi pelajaran dapat diseragamkan; proses belajar menjadi lebih menarik dan jelas; lebih interaktif; efisiensi dalam waktu dan tenaga; dapat meningkatkan kualitas hasil belajar siswa; memungkingkan proses belajar dilaksanakan dimana tempat dan waktu; dapat menumbuhkan sikap positif siswa terhadap materi dan proses belajar dan dapat merubah peran guru ke arah yang lebih positif dan produktif.

\section{Pembahasan}

Berdasarkan beberapa teori-teori yang berkaitan dengan media serta jenis-jenis media dan pentingnya media dalam proses pembelajaran seperti yang diungkapkan oleh Hamalik (1986) bahwa seyogyanya setiap pendidik dapat menggunakan media agar kualitas pembelajaran semakin baik. Penggunaan media pembelajaran yang menurut Kemp dan Dayton (1985) dapat merubah perang guru kearah yang lebih positif dan produktif, maka penggunaan media ini harus digalakkan.

Selain itu penggunaan media pembelajaran menurut Maulid (2017) guru dapat menggunakan Vibermixo yang menggabungkan antara materi ajar, animasi, grafik, audio visual, gambar dan pena penunjuk, sehingga mahasiswa lebih termotivasi di dalam memperoleh ilmu dari proses belajar mengajar yang tercipta. Hal ini juga dapat digalakkan dalam proses belajar pada mata kuliah akuntansi yang selama ini diajarkan monoton kepada teori-teori dan sebagian praktek namun guru tidak berusaha mengenalkan kepada siswa jenisjenis dan bentuk aktiva, hutang dan modal dan cara-cara mencatatnya dalam masingmasing jenis transaksi.

Pengenalan terhadap objek yang diajarkan seperti bagaimana model buku kas kecil, buku kas umum serta buku bank serta format-format tagihan, serta model cek perusahaan sangat jarang diperlihatkan kepada siswa dalam bentuk media visual dalam proses pembelajaran. Hal ini ini penting menjadi perhatian agar apa yang dilakukan oleh mahasiswa dalam tahap pengumpulan bukti, pencatatan dan klasifikasi setiap transaski juga diharapkan dapat memahami phisik dan proses terjadinya bukti-bukti tersebut.

Penggunaan media seperti Vibermixo dalam proses belajar termasuk dalam proses belajar akuntansi juga sejalan dengan beberapa pendapat seperti Gagne (1985). Beliau mengatakan bahwa media adalah berbagai jenis komponen dalam lingkungan siswa yang dapat merangsang siswa dalam belajar. Hasil penelitian ini juga sejalan dengan Haryanto (2012), Luh Putu Spyana Wati dan Kadek Yogi Parta Lesmana (2016) yang mendapati bahwa penggunaan media belajar dapat mengurangi beban guru dan hasilnya dapat menigkatkan kualitas belajar siswa.

Hasil penelitian ini juga telah beberapa hasil penelitian terdahulu. Maya (2011), Saputra (2015), Ratminingsih (2016); Risa Panti Ariani, Ni Made Suriani, Ni Wayan

Jambura : Economic Education Journal,Volume. 1, Issue. 1 January 2019. 
Marti (2014); Okta (2013); Suryatnata (2014) dan Suweken-Gede (2013) yang menyatakan bahwa penggunaan media belajar dapat mengarahkan proses belajar yang menarik dan efektif dan lebih interaktif. Demikian juga hasil penelitian ini juga sejalan dengan hasil penelitian Clark (1983); SH Liu, HL Liao, JA Pratt (2009); Bull, Thompson, Searson, Garofalo (2008) dan Chen dan Bryer (2012) bahwa penggunaan media belajar dapat menumbuhkan sikap positif siswa terhadap materi dan proses belajar yang lebih jelas dan lebih menarik.

\section{Kesimpulan dan Saran}

Berdasarkan latar belakang dan fenomena yang telah dikemukakan, maka dapat disimpulkan bahwa proses pembelajaran sangat memerlukan media pembelajaran temasuk dalam proses pembelajaran akuntansi baik berdasarkan tujuan, manfaat dan fungsinya. Oleh karena itu penggunaan media pembelajaran dalam mata kuliah akuntansi seyogyanya menggunakan media pembelajaran terutama media Vibermixo yang menyatukan aspek materi ajar, animasi, grafik, audio visual, gambar dan pena penunjuk yang diharapkan dapat meningkatkan kualitas belajar.

\section{Daftar Pustaka}

Aguswedi.(2011).Makalah media. https://www.researchgate.net/deref/http $\%$ 3A\%2F\%2. belajarpsikologi.com.

Alavi,M; Yoo, Y and Vogel,D. (2017). Using Information Technology to Add Value to Management Education. https :// doi. Org $\angle 10.5465 / 257035$

Baker, R. (2014). Qualitative research in accounting \& management article information: Qualitative Research in Accounting \& Man- agement, 11(4), 1-10. http : // doi . org / http : // dx.doi.org/10.1108/QRAM-082014-0054

Braun, V. \& Clarke, V. (2013). Successful qualitative research. Sage Publication Ltd. ISBN: 978-01-84787-581-5

Briggs, L. J., and Wager, W. W. (1981). Handbook of procedures for the design of instruction (2nd ed.) Englewood Cliffs, NJ: Educational Technology Publications. https://link.springer.com/article/10.1007/B F02299731

Bruner, J. S. (1957). Going beyond the information given. New York: https://int.search.tb.ask.com/search/GGm ain.jhtml? searchfor=Bruner\%2C+J.+S.+(19

57).+Going+beyond+the+information+give n. + New + York\%3A\&enableSearch=true\&r drct=no\&st=sb\&tpr=omni\&p2=\%5EBNF\% 5Expt567\%5ES28101\%5Emy\&ptb=B28819 9F-6DAE-4136-8350-

FB75C543B96D\&n=78494ff0\&si=EAIaIQob ChMI997mJKH3AIViBJoCh1rAAYmEAEYASAAE gLXePD_BwE

Bull,G; Thompson,A; Searson,M and Garofalo, J. (2008) Formal learning empowers the teacher. Informal Learning empowers. https://paulgordonbrown.com/2015/03/19/ formal-learning-empowers-the-teacherinformal-learning-empowers-the-student/

Chen, $\mathrm{B}$ dan Bryer, $\mathrm{T}$ (2012). The use of social media for academic practice: a review of literature.

ttps://uknowledge.uky.edu/cgi/viewconte nt.cgi?article $=1015 \&$ context=kjhepp

Cici-Fatma, I. (2015). Pengaruh penggunaan Media LCD dalam pembelajaran ekonomi terhadap hasil belajar siswa kelas $\mathrm{X}$ di SMA Negeri Tapa. Artikel Fakultas Ekonomi Universitas Negeri Gorontalo.

Clark, R. E. (1983). Reconsidering research on learning from media. Review of Educa-

Jambura : Economic Education Journal,Volume. 1, Issue. 1 January 2019. 
tional Research 53 (Winter 1983): 44559. http://www.uky.edu/ gmswan3/609/ Clark_1983.pdf

Clark, R.E. \& Salamon, G. (1986). Media in teaching. In M.C. Wittrock, ed. The third handbook of research on teaching, 468. Chicago, IL: Macmillan.

Creswell, J. (2013). Qualitative inquiry and research design. Chosing among five approaches (3rd Ed.). London: Sage publication Inc. http://doi.org/10.1111/1467-9299.00177

Dale, E.(1969). A significant contributor to the field of educational technology. Educational Technology, 47(6), 56.

Denzin, N. (2010). The qualitative manifesto: A call to arms. Walnut Creek, CA: Left Coast Press

Dimas,Q, Erna- Laurensia,A dan Irama,N. (2016). Pengembangan Media Pembelajaran Tematik Berbasis Mind Maping Sd Kabupaten Ngada Flores. Jurnal Pendidikan Indonesia, 5 (02),176-182.

Dit.PSMA.2017. Implementasi Pengembangan Kecakapan Abad 21 Dalam perencanaan pelaksanaan pembelajaran

(RPP). DirektoratPembinaan Sma

Direktorat Jenderal Pendidikan Dasar dan Menengah Kementerian Pendidikan dan Kebudayaan

Dupree, D; Marder, M. (1984). Principles of Accounting. Addison Wesley Publishing Company. California.

Febrianto, P.(2012). Meningkatkan belajar siswa melalui penggunaan Lembaran Kerja Siswa (LKS) mata pelajaran IPS Ekonomi. Artikel Fakultas Ekonomi Universitas Negeri Gorontalo.

Fernández-Martínez, A; Hernández-García, A; Gallardo-Antolín (2017). International Speech ... Multimedia Tools and Applications,

1-31. http://scholar.google.es/citations?user=f8v QCOAAAAAJ\&hl=es

Gagne, R. M., (1985) The Conditions of Learning and Theory of Instruction. New York: CBS College Publishing. https://int.search.tb.ask.com/search/GGm ain.jhtml?searchfor=Gagne $\% 2 \mathrm{C}+\mathrm{R} .+\mathrm{M} . \% 2$ $\mathrm{C}+(1985)+$ The+Conditions+of+Learning $+\mathrm{a}$ nd+Theory+of+Instruction.+New+York\%3 $\mathrm{A}+\mathrm{CBS}+$ College+Publishing.\&enableSearc $\mathrm{h}=$ true\&rdrct $=$ no\&st $=$ sb\&tpr $=$ omni\&p $2=\%$ 5EBNF\%5Expt567\%5ES28101\%5Emy\&ptb $=$ B288199F-6DAE-4136-8350-

FB75C543B96D\&n=78494ff0\&si=EAIaIQob ChMI997-

mJKH3AIViBJoCh1rAAYmEAEYASAAE gLXePD_BwE

Hamalik,O. (1994). Media pendidikan. (Cetakan ke-7).Penerbit PT Citra Aditya Bakti. Bandung.

Hart,T. (2001). From information to transformation: Education for the evolution Of consciousness.Academy of Management Journal, 40 (6). https : // www. amazon. Com / Information-TransformationEducation-Consciousness-Counterpoints / dp / 1433105918

Haryanto. (2012). Pengertian media. https://www.researchgate.net/deref/http $\%$ 3A\%2F\%2.Edi.

Kemp dan Dayton (1985). Planning and producing instructional media. https://www.amazon.com/Planning-

Producing-Instructional-MediaJerrold/dp/0060435887

Laurillard,D.(2002). Rethinking university teaching: A conversational framework for the effective use of learning technologies. https://www.amazon.com/RethinkingUniversity-Teaching-ConversationalTechnologies/dp/0415256798

Leavy, P. (2014). The oxford handbook of qualitative research. ( Oxford University Press Inc.

Jambura : Economic Education Journal,Volume. 1, Issue. 1 January 2019. 
New York. https://books.google.com.my/books?id= Denzin,+N.+K.,+\%26+Lincoln,+Y.+S.+(2012).

Lebar, O. (2012). Penyelidikan kualitatif; pengenalan kepada teori dan metod (Edisi Ke IV). Selangor-Kualalumpur: Universiti Pendidikan Sultan Idris (UPSI).

Liu,S; Liao,H; Pratt,J. (2009). Impact of media richness and flow on e-learning technology acceptance. http://citeseerx.ist.psu.edu/viewdoc/down load?doi=10.1.1.586.4518\&rep=rep1\&type $=$ pdf

Luh Putu Spyana Wati dan Kadek Yogi Parta Lesmana. (2016). Pengaruh model dan media pembelajaran Terhadap Hasil Belajar Kemampuan Dasar Senam Lantai Pada Mahasiswa Jurusan Penjaskesrek Undiksha.

https://www.researchgate.net/publication /314084053_pengaruh_model_dan_media _pembelajaran_terhadap_hasil_belajar_ke mampu-

an_dasar_senam_lantai_pada_mahasiswa _jurusan_penjaskesrek_undiksha

Marohaini, Y. (2013). Penyelidikan kualitatif: pengalaman kerja lapangan. (Edisi ke 5). Universiti Malaya. Kuala Lumpur-Malaysia

Maulid. 2017. Pengembangan Media Vibermixo dalam Meningkatkan Aktivtas dan Hasil Belajar Bahasa Inggris Siswa Kelas VII. Laporan Inovasi Pembelajaran. Kesharlindung Dikdas Kementerian Pendidikan dan Kebudayaan RI.

Maulid. 2018. Strategi Pembelajaran E-ril GB-GK (Education Of Real Interactive Learning Guru Besar Guru Kecil). Laporan Inovasi Pembelajaran. Kesharlindung Dikdas Kementerian Pendidikan dan Kebudayaan RI.

Meigs, R and Meigs, M; Bettner,M; dan Whittington, R.(1996). Accounting.the basis for business decisions. New York. The McGraw-Hill Companies, Inc.

Merriam, S. (2009). A guide to design and implementation. Revised and expanded from Qualitative research and case study applications in education. (2nd Ed.). 989 Market Street, San Francisco: Jossey-BassWiley

Miles, M., Huberman, A., \& Saldana, J. (2014). Qualitative data analysis. a methods sourcebook (3rd Ed.). London: Sage publication Inc

Miles, M., Huberman, A., \& Saldana, J. (2014). Qualitative data analysis. a methods sourcebook (3rd Ed.). London: Sage publication Inc

Moran, $\mathrm{M}$; Seaman, J; Tinti-Kane, $\mathrm{H}$ and Babson (2011). Teaching, Learning, and Sharing: How Today's Higher Education Faculty Use Social Media Survey Research Group. https://files.eric.ed.gov/fulltext/ED535130. pdf

Patton, M.Q. (2015). Qualitative research and evaluation method. (4 $4^{\text {th }}$ Ed.). Sage Publication, Inc.ISBN: 978-1-4129-7212-3

Ratminingsih (2016). Efektivitas media audio pembelajaran B. Inggris berbasis lagu. http://ejournal.undiksha.ac.id/index.php/J PI/article/view/8292/5508.

Richards, L., \& Morse, J. (2013). Qualitative methods ( $3^{\text {rd }}$ Ed.). USA. Sage publication Inc.

Ridder, H., \& Hoon, C. (2009). Introduction to the special issue: qualitative methods in research on human resource management. Human Resource Management, 23(2), 93106. http://doi.org/DOI 10.1688/18620000_ZfP_2009_02_Ridder.

Risa Panti Ariani, Ni Made Suriani, Ni Wayan Marti. (2014). Pengembangan media pembelajaran berdasarkan hasilhasil penelitian boga sebagai usaha peningkatan mutu pan-

Jambura : Economic Education Journal,Volume. 1, Issue. 1 January 2019. 
gan.http://download.portalgaruda.org/art icle.php? article $=305077 \& v a l=5112 \&$ title $=P$ engem-

bangan $\% 20$ Media\%20Pembelajaran $\% 20 \mathrm{Be}$ rdasarkan\%20Hasil-

Hasil\%20Penelitian\%20Boga\%20Sebagai\% 20Usaha\%20Peningkatan $\% 20 \mathrm{Mu} \% 20$ Pang an

Saputra, D. (2015). Makalah. pengertian media pembelajaran.

https://www.researchgate.net/publication /315105651_pentingnya_penggunaan_me dia_pembelajaran_untuk_meningkatkan_ prestasi_belajar_siswa

1.1 Sean,B.E; Joseph,W; Nicholas,A. (2006). The Determinants of Students' Perceived Learning Outcomes and Satisfaction in University Online Education: An Empirical Investigation https://doi.org/10.1111/j.15404609.2006.00114.x

Silfani, N. (2015). Pengaruh penggunaan media pembelajaran terhadap aktivitas belajar siswa pada mata pelajaran ekonomi.
Artikel Fakultas Ekonomi Universitas Negeri Gorontalo.

Suweken Gede. (2013). Pengintegrasian media pembelajaran virtual berbasis geogebra untuk meningkatkan keterlibatan dan pemahaman konsep matematika siswa kelas Viii Smpn 6 Singaraja.http://ejournal.undiksha.ac.id/index.ph p/JPI/article/view/2172/1888

Tracy, S. J. (2010). Qualitative quality: eight a big tent criteria for excellent qualitative research. Qualitative Inquiry, 16(10), 837851.http://doi.org/10.1177/10778004103831 21

Welsch, GA; Short, DG. (1987). Fundamentals Of Financial Accounting. Fifth Edition. Irwin. Illinois.

Yin, R. (2009). Case study research design and methods ( $4^{\text {th }}$ Ed.). London: Sage Publication Inc.

Yin, R. K. (2014). Case study research: design and methods Applied social research methods. ( $5^{\text {th }}$ ed.). Thousand Oaks, CA: Sage. (ISBN 978-1-4522-4256-9)

Jambura : Economic Education Journal,Volume. 1, Issue. 1 January 2019. 